\title{
Numerical evaluation of three-dimensional scarf repairs in carbon-epoxy structures
}

\author{
A.M.G. Pinto, R.D.S.G. Campilho, M.F.S.F. de Moura, I.R. Mendes
}

\begin{abstract}

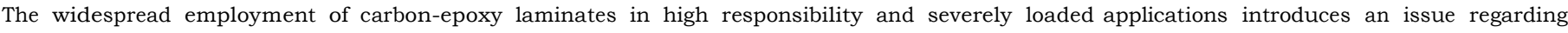

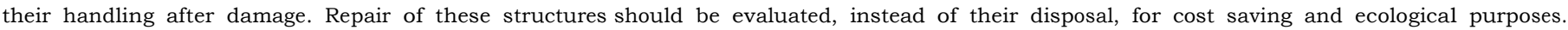

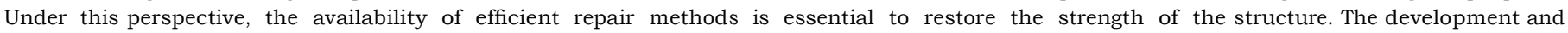

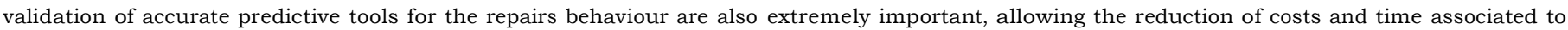

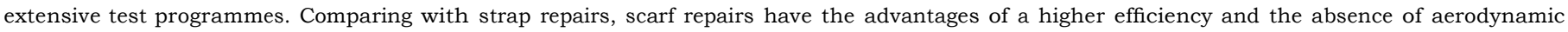

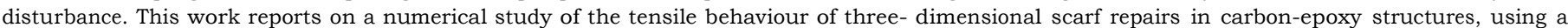

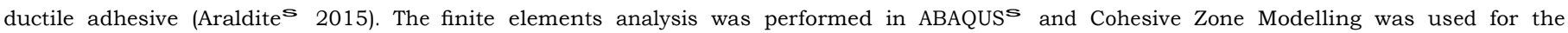

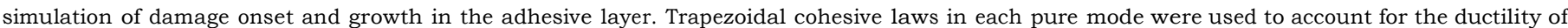

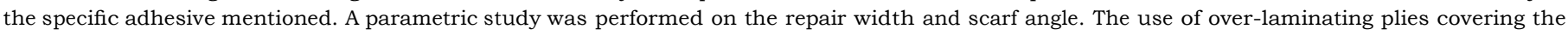

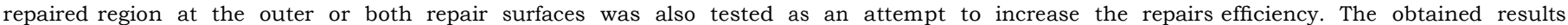
allowed the proposal of design principles for repairing composite structures.
\end{abstract}

Keywords: Epoxy/epoxides, Composite, Finite element stress analysis, Fracture, Repair

\section{Introduction}

Carbon-fibre reinforced plastic (CFRP) components are being more and more used in structures demanding a high performance because of their superior characteristics (such as high strength, high stiffness, long fatigue life and low density) [1]. In spite of these advantages, CFRP materials usually show a high sensitivity to temperature, moisture and accidental impacts. Thus, repair strategies should always be included in the quality assurance schedule of these composite structures [2]. Bonding of patches with adhesives, which provides durable and resistant unions [3-8], is being increasingly used in repairs. Typically, the initial strength and stiffness of the damaged components cannot be restored using this technique without a significant weight penalty. Thus, a substantial amount of research has been carried out in the last decades on the development of efficient adhesively bonded repairs and on adhesives technology [9-17]. Several studies are available for the repair of composite panels [10-13], including finite element $(\mathrm{FE})$ works describing predictive techniques for the strength of repaired structures [14-17]. Unlike the single-strap solution, scarf repairs do not cause a substantial bending of the components, which reduces peel stresses [18-22]. Moreover, shear stress distributions along the bond length are more uniform than for single and double-strap repairs, due to the tapering effect at the scarf edges [23]. The outcome of the optimization of stresses is a higher strength for the same bond area than strap repairs [24], which renders scarf repairs more suited to critical applications [25]. The substantial or full strength recovery achieved by this method, provided that the repair is correctly designed, usually makes scarf repairs as permanent [26-29]. Conversely to strap techniques, scarf repairs are also flush with the damaged structure, which is an important advantage since aerodynamic disturbance is prevented and stealth characteristics (if relevant) are not compromised. In specific cases, a flush surface may be imposed to avoid interference between components. The scarf repair technique has become particularly important in the last decades, due to the increasing use of sandwich panels in aircraft structures $[28,30]$. 
Despite all of these advantages, scarf repairs are more difficult to execute, which reflects on higher costs. In addition, they require a large repair area, since relatively small angles are necessary to restore the strength of components $[27,29,31]$. The execution of this repair initiates by machining a tapered cavity to remove the damaged material and to provide the repair geometry. This is usually performed with a hand-held pneumatic router or grinder. Two solutions can be adopted for the patch application: adhesively bonding a conical patch with the complementary shape of the laminate [23,32-34], or filling the scarfed hole with increasing diameter pre-preg plies, followed by simultaneous curing with the adhesive film, in the autoclave or using a vacuumbag [35-38]. The implementation of a pre-cured and machined scarf patch to a composite fuselage skin is described in the work of Bauer and Maier [39]. The high quality repair achieved with this technique met all the structural requirements defined in the repair specifications manual of the aircraft.

In tension, experimental and $\mathrm{FE}$ studies show an exponentially increasing strength of scarf assemblies (joints or repairs) with the reduction of the scarf angle (a), due to the corresponding increase of bond area [29,31,40-43]. On the failure modes of these assemblies, it was found that values of a below approximately 21 led to cross-sectional failures of the laminates outside the repaired region, while bigger values typically yielded failures in the adhesive layer $[23,33,44]$. Charalambides et al. [13] tested experimentally scarf repairs with $a^{1 / 4} 21$. Four distinct failures were identified, depending on the temperature and moisture conditions, as well as the type of load (static or dynamic). As a complement, the same authors [14] performed a two-dimensional (2D) FE analysis to simulate the four failure modes of the repairs. The failure loads were estimated by different failure criteria and compared with the experiments, with promising results. Odi and Friend [45] compared the stress distributions between three different $\mathrm{FE}$ approaches to simulate stepped and $\mathrm{a}^{1 / 4} \mathrm{4} 1 \mathrm{CFRP}$ scarf repairs under tension, using equivalent orthotropic elastic properties for the CFRP components. For the scarf repairs, shear stresses in the adhesive were nearly constant, leading to a high efficiency, as the adhesive failed simultaneously at all the bond length. Three-dimensional (3D) ply-level analyses of composite repairs have recently become feasible, as a result of the great evolution in the processing capabilities of common desktop computers [46]. In recent years, good quantitative predictions were achieved on the static strength of adhesively bonded repairs with Cohesive Zone Models (CZMs) coupled with FE simulations $[47,48]$. The use of this technique, which accounts for the progressive damage evolution, is particular meaningful for scarf repairs due to the difference between damage initiation and failure loads. This is because of singularities at the bond edges of a substantially higher magnitude than the stresses along the adhesive bond [49-52]. The work of Campilho et al. [23] validates with experiments of a developed trapezoidal CZM applied to tensile loaded 2D scarf repairs on CFRP laminates, for values of a between 21 and 451. To account for the experimental fractures, the cohesive failure of the adhesive layer and composite interlaminar and intralaminar (in the transverse and fibre directions) failures were considered at different regions. The corresponding pure modes I and II laws were estimated with an inverse modelling technique. The accurate predictions of the fracture loads and failure mechanisms validated the proposed technique.

This study reports on the tensile behaviour of 3D scarf repairs in CFRP structures, using a ductile adhesive (Araldites 2015). Since the proposed numerical methodology was already validated with experiments in previous works, giving accurate predictions $[47,48]$, the present research is restricted to a purely numerical optimization analysis of the repairs that will allow the definition of repair principles for composite structures. Traditionally, the design of scarf repairs is based on 2D models, as a simplification of the 3D geometry [53-56]. The primary motivation for this work stems from the known inconsistencies between the 2D approximations and the $3 \mathrm{D}$ repair $[17,56-59]$. In fact, with the $2 \mathrm{D}$ simplification, stresses along the scarf bond are regarded as constant in the width direction of the repairs, thus neglecting the concentrations at the scarf edges near the longitudinal mid-plane of the 3D repair $[29,56]$. Moreover, the 2D simplified geometry does not capture the typical 3D stress effects of these repairs $[60,61]$, which may result on a premature catastrophic failure at or near the interfaces between the composite and the adhesive layer [51]. The FE analysis was performed in ABAQUS ${ }^{\mathbf{s}}$ and used CZMs for the simulation of damage onset and growth in the adhesive layer. Trapezoidal cohesive laws in each pure mode were used to account for the ductility of the adhesive used. A parametric study was performed on the repair width and scarf angle. The use of over-laminating plies covering the repaired region at the outer or both repair surfaces was also tested as an attempt to increase the repairs efficiency. The results obtained allowed the establishment of design principles for repairing.

\section{Numerical analysis}

\subsection{Cohesive Zone Model}

The cohesive fracture of an adhesive layer of Araldite ${ }^{\mathbf{s}} 2015$ with thickness $\left(t_{\mathrm{A}}\right)$ of $0.2 \mathrm{~mm}$ was simulated with a mixed-mode (I+ II+ III) CZM. A trapezoidal law between stresses (S) and relative displacements $\left(\mathrm{d}_{\mathrm{r}}\right)$ between homologous points of the cohesive elements with zero thickness was considered (Fig. 1), to account for the adhesive ductility $[23,47,48]$. The formulation allows a mixed-mode behaviour, in which damage onset is predicted using a quadratic stress criterion:

$$
\begin{gathered}
\left(\frac{\sigma_{I}}{\sigma_{\mathrm{u}, \mathrm{I}}}\right)^{2}+\left(\frac{\sigma_{\mathrm{II}}}{\sigma_{\mathrm{u}, \mathrm{II}}}\right)^{2}+\left(\frac{\sigma_{\mathrm{III}}}{\sigma_{\mathrm{u}, \mathrm{III}}}\right)^{2}=1 \quad \text { if } \sigma_{1}>0, \\
\left(\frac{\sigma_{\mathrm{II}}}{\sigma_{\mathrm{u}, \mathrm{II}}}\right)^{2}+\left(\frac{\sigma_{\mathrm{III}}}{\sigma_{\mathrm{u}, \mathrm{II}}}\right)^{2}=1 \quad \text { if } \sigma_{\mathrm{I}} \leq 0,
\end{gathered}
$$

where $\mathrm{s}_{i}\left(i \frac{1 / 4}{\mathrm{I}} \mathrm{I}, \mathrm{II}, \mathrm{III}\right)$ represent the stresses in each mode and $\mathrm{su}_{\mathrm{u}, i}$ (i1/4I, II, III) the corresponding local strengths. The first Eq. (1) can be rewritten as a function of the relative displacements:

$$
\left(\frac{\delta_{1 \mathrm{~m}, \mathrm{l}}}{\delta_{1, \mathrm{I}}}\right)^{2}+\left(\frac{\delta_{1 \mathrm{~m}, \mathrm{II}}}{\delta_{1, \mathrm{Il}}}\right)^{2}+\left(\frac{\delta_{1 \mathrm{~m}, \mathrm{III}}}{\delta_{1, \mathrm{II}}}\right)^{2}=1
$$

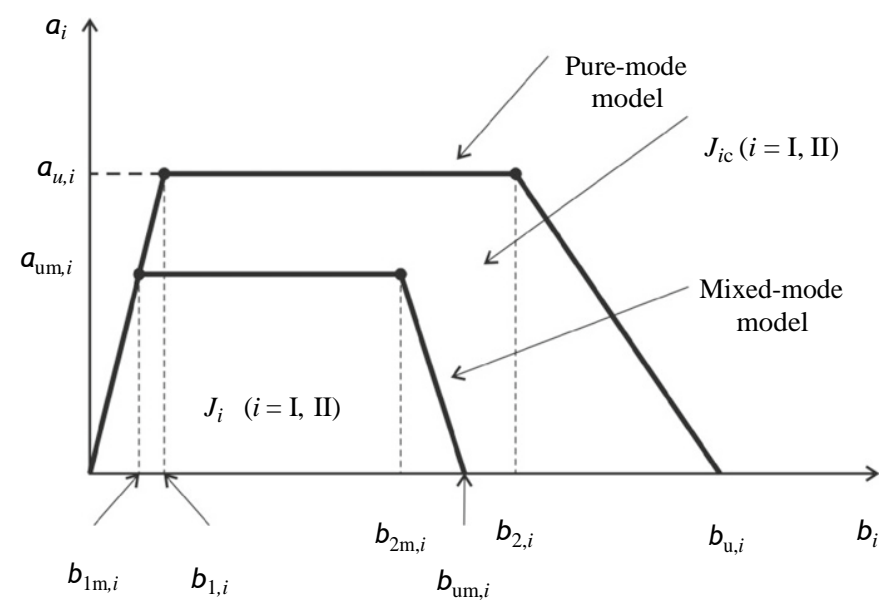

Fig. 1. The trapezoidal softening law for pure-mode and mixed-mode 
$\mathrm{d}_{1, i}\left(i \frac{11 / 4}{\mathrm{I}}, \mathrm{II}, \mathrm{III}\right)$ are the pure mode relative displacements at damage initiation and $\mathrm{d}_{1 \mathrm{~m}, i}\left(i \frac{11 / 4}{\mathrm{I}}\right.$, II, III) the corresponding mixedmode ones. Stress softening onset was predicted using a criterion $\mathrm{sim}_{2}$ ilar to $(2)$ : $\mathrm{C}_{2}$

$$
\left(\frac{\delta_{2 \mathrm{~m}, \mathrm{I}}}{\delta_{2, \mathrm{I}}}\right)^{2}+\left(\frac{\delta_{2 \mathrm{~m}, \mathrm{II}}}{\delta_{2, \mathrm{II}}}\right)^{2}+\left(\frac{\delta_{2 \mathrm{~m}, \mathrm{III}}}{\delta_{2, \mathrm{III}}}\right)^{2}=1 \text {. }
$$

stress sottening onset and $\mathrm{d}_{2 \mathrm{~m}, i}\left(l^{1 / 4} / \mathrm{I}, \mathrm{Il}, \mathrm{III}\right)$ the corresponding mixed-mode ones. Crack growth was simulated by the linear energetic criterion:

$$
\frac{J_{\mathrm{I}}}{J_{\mathrm{Ic}}}+\frac{J_{\mathrm{II}}}{J_{\mathrm{Il} \mathrm{c}}}+\frac{J_{\mathrm{III}}}{J_{\mathrm{III}}}=1 \text {, }
$$

being $J_{i c}\left(i \frac{1}{4} \mathrm{I}\right.$, II, III $)$ the fracture energy in the respective pure mode. When Eq. (4) is satisfied at a given integration point, damage grows and stresses are released, apart from normal compressive ones. A detailed description of this model can be found in the work of Campilho et al. [62].

\subsection{Fracture simulation}

In the numerical models, crack propagation with cohesive elements was only considered for the cohesive failure of the adhesive layer. Apart from this possibility, a stress-based criterion was assumed for the tensile failure of the composite parts. For the 01 plies, oriented in the load direction, the experimentally determined strength from unidirectional specimens was considered (1280 $7177 \mathrm{MPa}$, the average value was used for the prediction of failure). For the 901 plies, i.e., experiencing a matrix failure, typical values from the literature were used (E40 MPa) [23]. In the numerical models, failure was predicted as the load of patch debonding onset [63], guaranteeing that neither the laminate nor the patch attained the mentioned strengths of the two sets of plies. The prospect of interlaminar and intralaminar failures near the scarf was not considered, despite the chance of this occurrence [23], owing to slightly smaller cohesive properties for these propagations compared with the properties of some structural adhesives. Nonetheless, this procedure was adopted due to the modelling difficulties and additional computational time required to simulate these localized fractures, which do not influence by a significant amount the global characteristics of 3D repairs such as the ones proposed in this work. Actually, these are mostly ruled by the laminate properties and instant of patch debonding, rather than by the strength at the repaired region [63]. This is due to the clear difference between the composite tensile properties in the fibres direction and the adhesive and composite (interlaminar and intralaminar) properties. Under this simplification hypothesis, the predictions should be interpreted in relative terms between the different tested solutions, allowing the establishment of design principles for these repairs, instead of being viewed as precise quantitative predictions. The adhesive layer was introduced in the numerical models by the trapezoidal CZM presented previously, with experimentally defined properties for the specific value of $t_{\mathrm{A}}$ used in the repairs. The adhesive layer elastic stiffness in tension and shear (up to $d_{1, i}$, Fig. 1) was specified from the experimentally measured values of Young's modulus $\left(E^{1 / 4} 1850 \mathrm{MPa}\right)$ and shear modulus $\left(G^{1 / 4650}\right.$ MPa) [64], as detailed in the work of Campilho et al. [62]. The other necessary parameters to define the trapezoidal law are the local strengths $\left(\mathrm{S}_{\mathrm{u}, i}\right)$, the second inflexion points $\left(\mathrm{d}_{2, i}\right)$ and the fracture energies $\left(\mathrm{J}_{i \mathrm{c}}\right)$. To account for the known dependency of these quantities with $t_{\mathrm{A}}$ [23], in this work, the cohesive laws of the adhesive layer in pure modes I and II were estimated by Double Cantilever Beam (mode I) and End-Notched Flexure (mode II) tests with the same value of $t_{\mathrm{A}}$, using inverse modelling $[65,66]$. The pure mode III cohesive law was equalled to the pure mode II one as an approximation [62]. Table 1 presents the cohesive parameters of the pure modes I and II laws used to simulate an adhesive layer of Araldite 2015 with $t_{\mathrm{A}}{ }^{1 / 40.2} \mathrm{~mm}$.

\subsection{Numerical conditions}

Fig. 2(a) shows the scarf repair geometry and characteristic dimensions. The Outer Edge of the Scarf (OES) and Inner Edge of the Scarf (IES) loci are identified in the figure. The characteristic dimensions of the scarf repair are the laminate length $(a)$, width $(b)$ and thickness $\left(t_{\mathrm{P}}\right)$, hole diameter $(d), t_{\mathrm{A}}$ and $\mathrm{a}$. The parameter a can be defined as the angle between the scarf and the horizontal plane. The scarf length $\left(L_{\mathrm{S}}\right)$ is intrinsically related to the chosen values of $\mathrm{a}$ and $t_{\mathrm{p}}$. The following dimensions were considered for the numerical analysis: $a^{1 / 4} 200 \mathrm{~mm}, b^{1 / 450}$ and $80 \mathrm{~mm}$, $t_{\mathrm{P}} 1 / 42.4 \mathrm{~mm}, d^{1 / 4} 10 \mathrm{~mm}, t_{\mathrm{A}}^{1 / 40.2} \mathrm{~mm}$ and $\mathrm{a}^{1 / 4} 101,151,251$ and 451 (for the repairs with $b^{1 / 4} 50 \mathrm{~mm}$ ) or $\mathrm{a}^{1 / 4} 51,101,151,251$ and 451 (for the repairs with $b^{1 / 4} 80 \mathrm{~mm}$ ). The minimum values of a were imposed by the respective values of $b$. Although small values of a are necessary for the repair to work in the preferential shear plane and to achieve a reasonable bond area, necessary to an efficient repair [31,67], scarf angles up to 451 , which may be imposed due to restrictions to the structure dimensions, were also analysed. Sixteen plies and $\left[\mathrm{O}_{2}, 90_{2}, \mathrm{O}_{2}, 9 \mathrm{O}_{2}\right]_{\mathrm{S}}$ lay-up laminates and patches were used in this analysis (considering a $0.15 \mathrm{~mm}$ ply unit thickness). Fig. 2(b) shows the numerical idealization of the scarf repair tensile test. Only $1 / 4$ of the laminate was modelled, by the use of symmetry conditions at the mid-transversal $(A)$ and midlongitudinal $(B)$ planes. The scarf repairs were simulated in ABAQUS $^{\boldsymbol{s}}$ with 3D models. The cohesive elements, used to extract stresses along the bond length and to simulate a cohesive failure

Table 1

Cohesive parameters in pure modes I and II to simulate an adhesive layer of Araldite $^{\mathrm{s}} 2015$ with $t_{\mathrm{A}} 1 / 40.2 \mathrm{~mm}$.

\begin{tabular}{lllll} 
Cohesive laws & $i$ & $J_{i c}(\mathrm{~N} / \mathrm{mm})$ & $\mathrm{Su}, i(\mathrm{MPa})$ & $\mathrm{d}_{2, i}(\mathrm{~mm})$ \\
\hline Adhesive layer & I & 0.43 & 23.0 & 0.01870 \\
& II & 4.70 & 22.8 & 0.1710
\end{tabular}
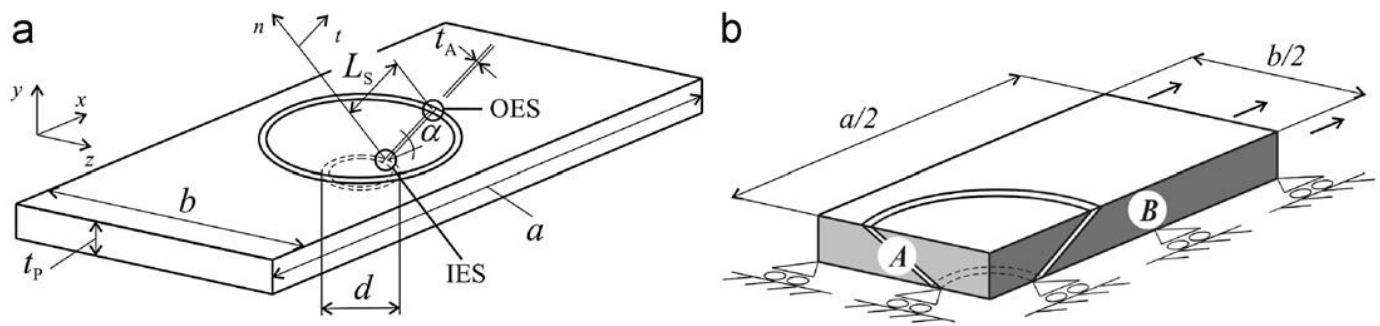

Fig. 2. Scarf repair geometry (a) and numerical idealization with symmetry conditions (b) 
a

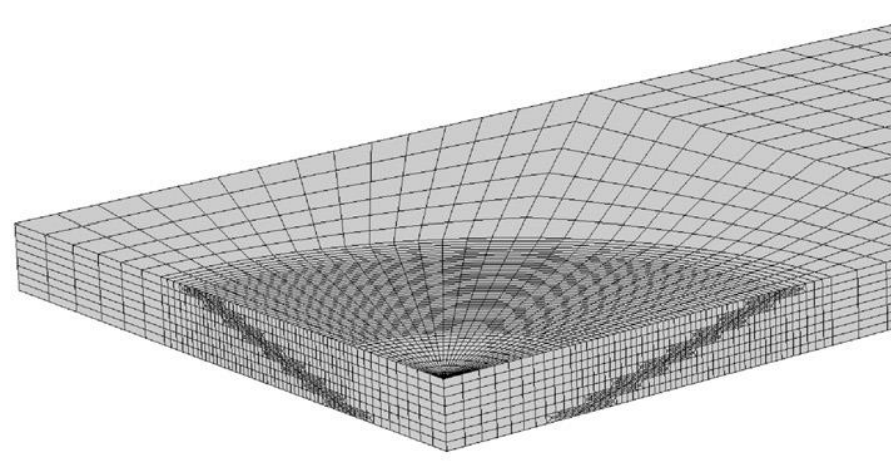

b

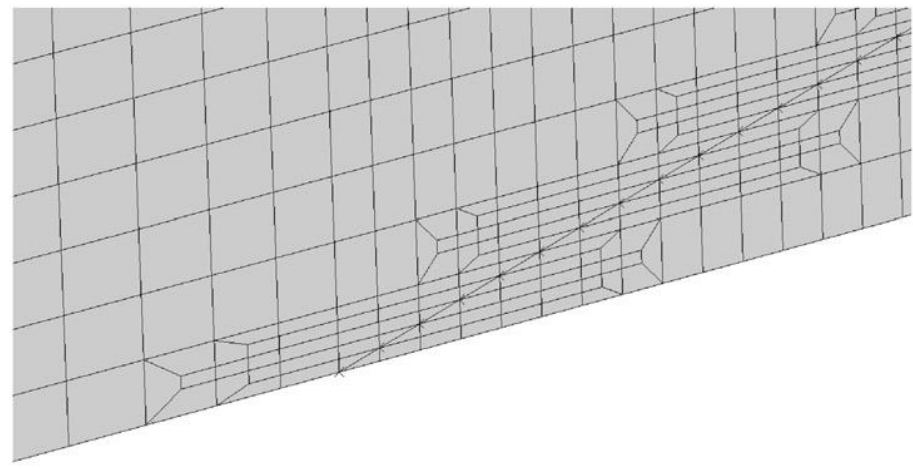

Fig. 3. Detail of the mesh at the repaired region (a) and at the IES (b) for the $\mathrm{a}^{1 / 4} 151$ repair $\left(b^{1 / 4} 50 \mathrm{~mm}\right)$.

Table 2

Ply mechanical properties of the CFRP laminates and patches.

\begin{tabular}{lll}
\hline$E_{1} 1 / 41.09 \mathrm{E}+05 \mathrm{MPa}$ & $\mathrm{n}_{12}{ }^{1 / 4} 0.342$ & $G_{12}{ }^{1 / 4} 4315 \mathrm{MPa}$ \\
$E_{2}{ }^{1 / 4} 8819 \mathrm{MPa}$ & $\mathrm{n}_{13^{1 / 4} 0.342}$ & $G_{13^{1 / 4} 4315 \mathrm{MPa}}$ \\
$E_{3}^{1 / 4} 8819 \mathrm{MPa}$ & $\mathrm{n}_{23^{1 / 4} 0.380}$ & $G_{23^{1 / 4}} 3200 \mathrm{MPa}$ \\
\hline
\end{tabular}

of the adhesive layer, were introduced in the numerical models along the scarf length. Cohesive elements allow the extraction of stresses in the directions tangent and normal to the scarf (coordinate system $t-n$ in Fig. 2(a)). The standard ABAQUS ${ }^{s}$ solid finite elements, which evaluate stresses at the Gauss points and, additionally, in the coordinate system $x-y$ (Fig. 2(a)), are not suited for these geometries $[29,31,68]$. A geometrical non-linear analysis was performed, using 8-node hexahedral and 6-node pentahedral solid finite elements available in ABAQUS ${ }^{5}$. Fig. 3 shows the mesh at the repaired region (a) and at the IES (b) for the $a^{1 / 4} 151$ repair $\left(b^{1 / 450} \mathrm{~mm}\right)$. The mesh is particularly refined at the scarf region, in the adhesive and in the laminate and patch, with 40 elements along $L_{\mathrm{S}}$ to ensure a bigger refinement at the loci of stress concentrations $[29,31,69]$. Thirty elements were considered for $1 / 4$ of the patch in the radial direction. At the scarf region, each group of two equally oriented and adjacent plies was modelled with five solid elements. Mesh coarsening was applied to reduce the number of elements outside this region. The laminate and patch were modelled as elastic orthotropic, considering the properties of Table 2 [70].

\section{Results}

\subsection{Stress analysis}

Normal $\left(\mathrm{S}_{\mathrm{n}}\right)$ and shear $\left(\mathrm{t}_{\mathrm{tn}}\right)$ stresses in the adhesive layer for scarf assemblies are practically constant for isotropic adherends or unidirectional composites $[31,43,45]$. This can be justified in light of a smaller load eccentricity than in lap or strap geometries $[27,70]$ and by the adherend tapering effect at the scarfed region $[23,27]$, and helps to the high efficiency of these assemblies relatively to the bond area. For layered composites with differently oriented plies, large variations of stresses develop, due to the stiffness variation between plies, even when the laminates to be joined have identical lay-ups $[23,29,68,71,72]$.

This section presents an elastic analysis of the adhesive layer stresses, for an easier understanding of the repairs fracture behaviour. Sn peel and $t_{t n}$ stresses along the bond line at plane $B$ are presented in Figs. 4 and 5, respectively, for the repairs with

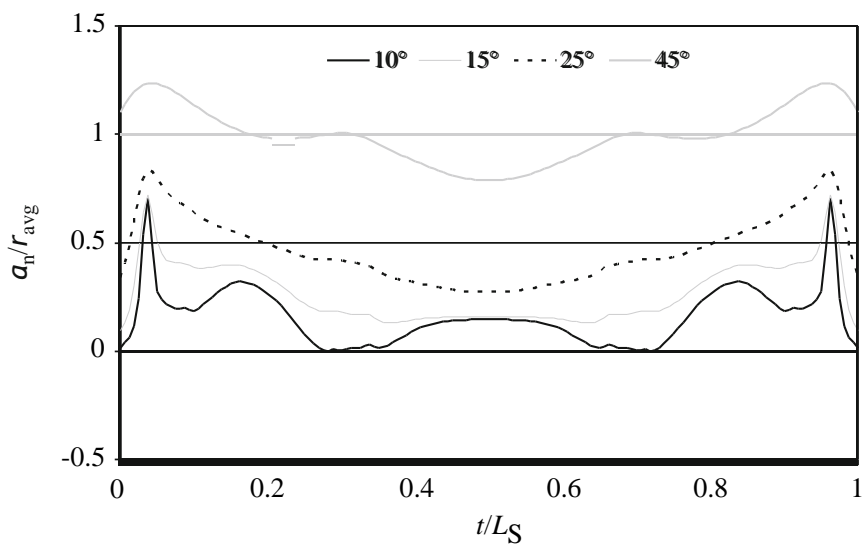

Fig. 4. Sn peel stress distributions in the adhesive layer for the different values of a (repairs with $b^{1 / 4} 50 \mathrm{~mm}$ ).

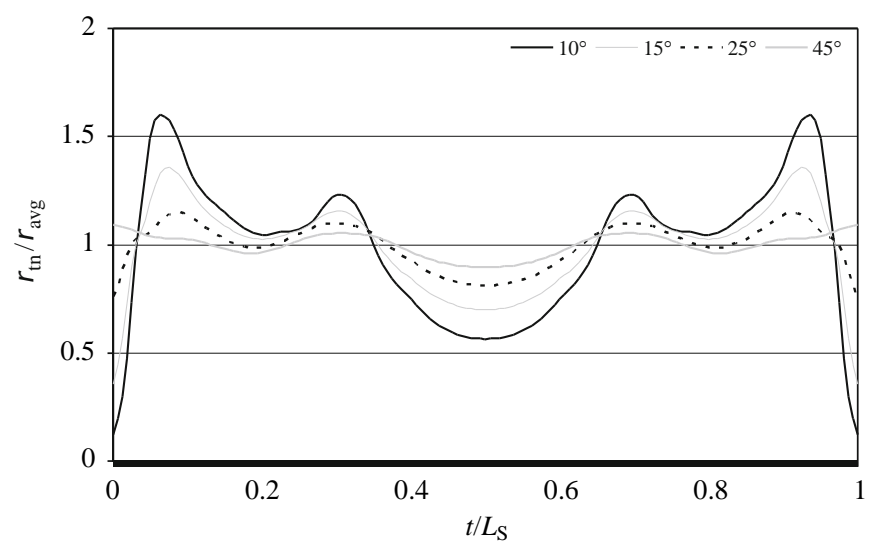

Fig. 5. ttn shear stress distributions in the adhesive layer for the different values of a (repairs with $b^{1 / 4} 50 \mathrm{~mm}$ ).

$b^{1 / 4} 50 \mathrm{~mm}$ and the corresponding values of a. This plane was selected for the analysis since it corresponds to the locus of higher magnitude of stresses $[68,73]$. Both stresses were normalized by the average shear stress along the scarf length for the respective value of a $\left(t_{\text {avg }}\right)$. $S_{n}$ peel stresses are much smaller in magnitude than $t_{\text {tn }}$ stresses for the smaller values of a. In fact, under these conditions, the repair is primarily loaded in shear $[31,53]$. However, Sn stresses gradually increase with a [74]. Inclusively, 
for a $a^{1 / 4} 451$ repair, $S_{n}$ stresses approach $t_{a v g}$ in magnitude. $S_{n}$ stress profiles are wavy, without a direct correspondence with the plies orientation, being tractive along $L_{\mathrm{S}}$. $t_{\mathrm{tn}}$ stress profiles are similar between the different values of a evaluated, despite the small reduction of peak $t_{\text {tn }}$ stresses magnitude with the increase of a. $t_{\text {tn }}$ stresses clearly reflect the differences in compliance between the plies adjacent to the adhesive $[29,68,72]$. Actually, they peak near the 01 plies because of their higher stiffness in the loading direction, while the adhesive layer has a constant stiffness [55]. $t_{\text {tn }}$ stress gradients between the regions of 01 and 901 plies gradually diminish with the increase of a. An increasing tendency for $S_{n}$ and $t_{t n}$ stresses was also found towards the IES and OES, which is consistent with the work of Campilho et al. [31], concerning the tensile behaviour of $2 \mathrm{D}$ unidirectional scarf repairs.

\subsection{Strength analysis for the standard scarf repairs}

Fig. 6 compares the load-displacement $(P-\mathrm{d})$ curves between the different values of a, considering $b^{1 / 4} 50 \mathrm{~mm}$. The values of $P$ and $\mathrm{d}$ are the direct output of the simulations, i.e., considering half-width and half-length of the repairs. The original curves were shifted by different values ( $1 \frac{1}{4} 0,0.05,0.10$ and $0.15 \mathrm{~mm}$ ) for an easier visualization. This figure shows an identical stiffness of the repairs and increasing values of $P$ with the decrease of a, whose reasoning was already discussed $[29,31,40,43]$. The stiffness reduction near the peak load is due to softening of the adhesive layer cohesive elements, in anticipation of patch debonding. Fracture of the repairs was identical for all the studied values of a, with a simultaneous fracture of the adhesive layer at the entire bond near plane $B$ after localized damage at the IES and OES, propagating swiftly in the radial direction of the scarf up to approximately 451 of plane $B$. An example of this fracture is presented in Fig. 7 for a $a^{1 / 4} 151$ repair $\left(b^{1 / 450} \mathrm{~mm}\right)$. These results

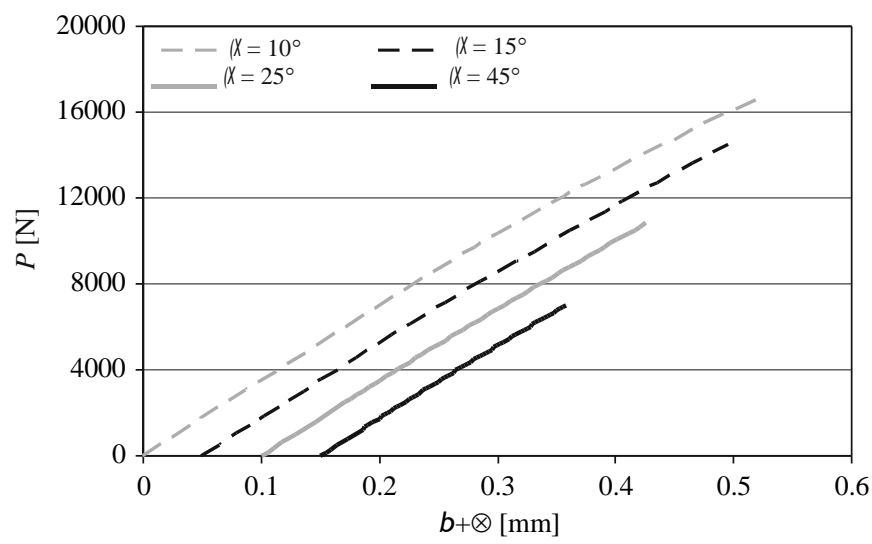

Fig. 6. Numerical $P$-d curves for the different values of a (repairs with $b^{1 / 450 ~ m m}$ ).

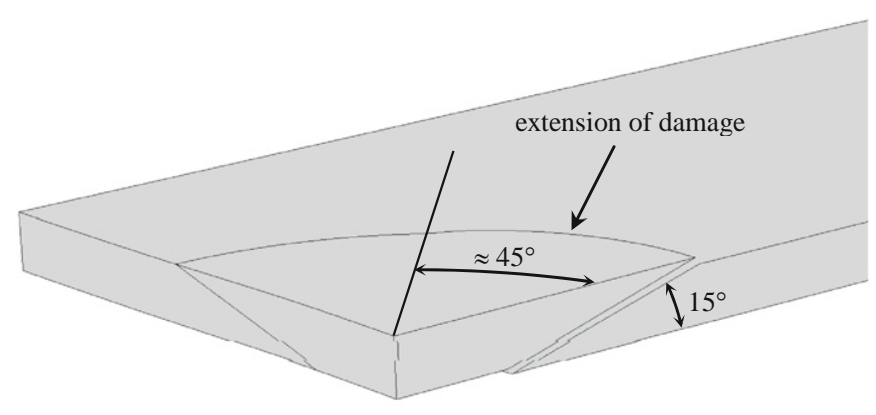

Fig. 7. Numerical failure for a $a^{1 / 4} 151$ repair $\left(b^{1 / 4} 50 \mathrm{~mm}\right)$. can be easily interpreted from the stress analysis presented previously (Figs. 4 and 5), i.e., by the higher magnitude of $\mathrm{S}_{n}$ and $t_{t n}$ stresses near the bond edges. The onset of fracture near plane $B$ and gradual radial propagation is due to peaking of $\mathrm{S}_{n}$ and $t_{t n}$ stresses at plane $B$, gradually diminishing with the increase of the angle from this plane $[68,73]$. Fig. 8 plots the efficiency of the repairs $(Z)$ as a function of a for the repairs with $b^{1 / 4} 50$ and $80 \mathrm{~mm}$. The value of $Z$ is defined by the quotient between the patch debonding onset load and the failure load of the undamaged composite. The failure load was determined by experimental tensile tests on three undamaged specimens with $b^{1 / 4} 15 \mathrm{~mm}$ and the same lay-up and thickness of the damaged laminates, giving an average value of failure stress and deviation of $6557134 \mathrm{MPa}$. For the calculations of $Z$, the average value was considered in the estimation of the failure load for the $b^{1 / 4} 50$ and $80 \mathrm{~mm}$ undamaged laminates, using the respective cross-sectional areas. In all the repairs, including in the study of the following section, it was checked that the failure strength of the 01 and 901 plies was not attained prior to patch debonding onset. The exponential increase of $Z$ with the reduction of $a$ is related to the corresponding increase of the bond area $[29,31,40,43]$. The values of $Z$ are slightly bigger for the repairs with $b^{1 / 4} 80 \mathrm{~mm}$, with an increasing difference to the $b 1 / 450 \mathrm{~mm}$ repairs as a diminishes. This can be explained by a larger influence of the laminate resistant area at the symmetry plane $A$ on the global characteristics of the repairs for $b^{1 / 4} 80 \mathrm{~mm}$, since the repair dimensions are similar for a given value of a. The best results are always granted by the smallest value of a, i.e., $\mathrm{a}^{1 / 4} 101$ for the $b^{1 / 4} 50 \mathrm{~mm}$ repair (ZE 42\%) and $\mathrm{a}^{1 / 4} 51$ for the $b^{1 / 4} 80 \mathrm{~mm}$ repair (Z E 55\%).

\subsection{Strength analysis for the scarf repairs with over-laminating plies}

An alternative to the use of very small values of a, required to fully restore the structure strength, consists on the application of external doublers (or over-laminating plies) adhesively bonded at the repaired region to protect the patch tips and to provide a larger cross-sectional area at the repaired region, thus increasing the strength of the repairs [34]. These plies are generally very thin and designed to follow the parent structure contour as closely as possible [75]. Although the most efficient solution is to bond overlaminating plies on both the laminate faces [13,14,76], a more practical solution consists on their application only on the outer face of the repair (upper surface in Fig. 2(a)) [38,77]. This choice can also be imposed by accessibility difficulties to the inner face of the composite structure, or be rendered unfeasible for sandwich laminates with composite faces [78]. Gunnion and Herszberg [68]

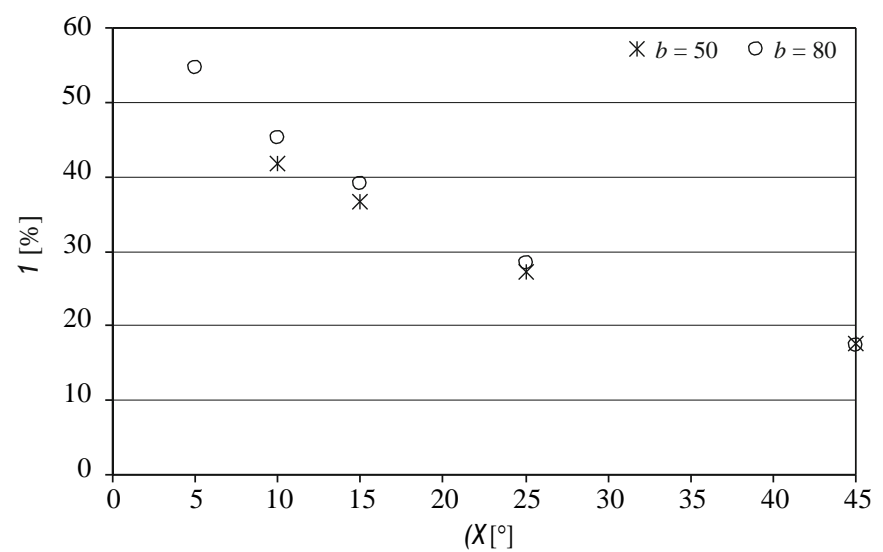

Fig. 8. Z as a function of a for the repairs with $b^{1 / 4} 50$ and $80 \mathrm{~mm}$. 
investigated the effect of an over-laminate on both faces of scarf joints with 16 and 32 plies laminates applied to the full length and width of the joints. This technique resulted in a significant drop on peak peel and shear stresses within the bond, which otherwise develop near the free edges. Different lay-ups and increasing the number of over-laminating plies from the initial analysis ( 2 plies) provided no significant differences in reducing peak peel and shear stresses. In the present work, an optimization study was carried out on the influence of using over-laminating plies on the value of $Z$ of the repairs, considering reinforcement only at the outer face of the repair (single reinforcement) and at both faces (double reinforcement). The over-laminate consisted of two plies of circular shape: a 01 ply adjacent to repair surface, covered by a 901 ply. This set-up was selected to account for a typical bi-axial loading, despite not being a symmetric lay-up. Fig. 9 shows the tested geometry, considering double reinforcement. Two values of overlap with the damaged structure at the outer face $(e)$ were tested for the single

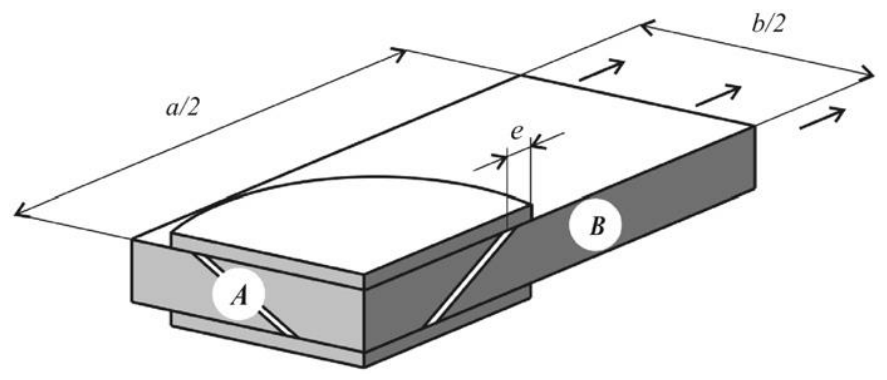

Fig. 9. Numerical idealization of the scarf repair with double reinforcement. reinforcement: 2.5 and $5 \mathrm{~mm}$. For the double reinforcement, only $e^{1 / 4} 5 \mathrm{~mm}$ was equated, due to evidence of better results. Bigger values were not considered, to guarantee a minimum clearance with the repair edges for the smallest values of a (for each value of $b$ ). An example of the mesh refinement for this repair configuration is shown in Fig. 10, illustrating the mentioned limitation. Identical dimensions were considered for the reinforcements on both faces for fabrication simplification purposes and maximum effect of the over-laminates, although the inner face of the repairs may be over-reinforced [76]. Fracture for the different tested solutions depended on the type of reinforcement (single or double) and value of a. For the single reinforcement and bigger values of a, the asymmetry of loading induced by the over-laminating plies led to a slight transverse deflection of the laminate [38] that caused premature crack initiation near plane $B$ at the IES (unreinforced region). This damage then propagated towards the OES and to the overlap region, simultaneously to radial growth of damage in the direction of plane A. Fig. 11(a) shows damage initiation at the IES for a $a^{1 / 4} 451$ repair with $b^{1 / 4} 50 \mathrm{~mm}$ and $e^{1 / 4} 2.5 \mathrm{~mm}$. For the smaller values of $a$, fracture was simultaneous over the entire bond and overlap region. Although the transverse deflection of the repairs still subsisted, the bigger taper length in the laminate and patch allowed a slight bending of the scarf tips, enough to avoid a premature fracture at the IES. Fig. 11 (b) relates to a $a^{1 / 4} 101$ repair with $b^{1 / 4} 50 \mathrm{~mm}$ and $e^{1 / 42.5} \mathrm{~mm}$. The asymmetry of load induced by the over-laminating plies is prevented using double reinforcement. Thus, for the bigger values of a the entire scarf bond failed simultaneously near plane $B$, whilst the overlapping plies were kept under load (Fig. 12(a)). Increasing further the load causes the detachment of the over-laminate at the outer face, followed by the one at the inner face, both from plane $B$ towards a

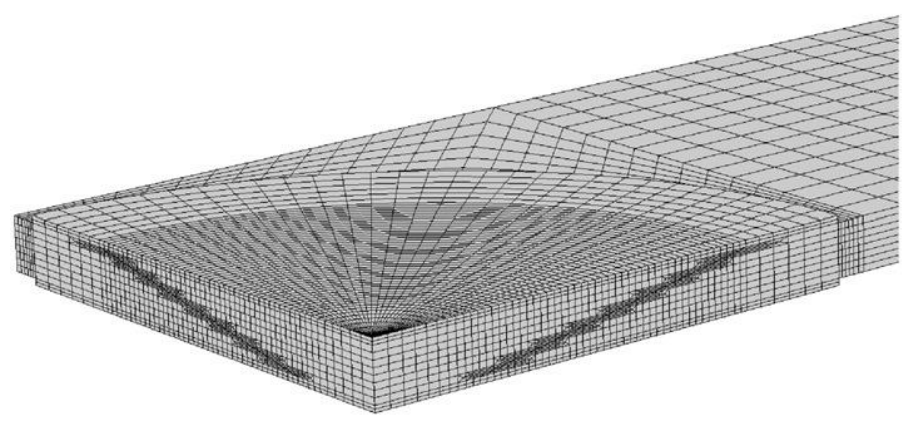

b

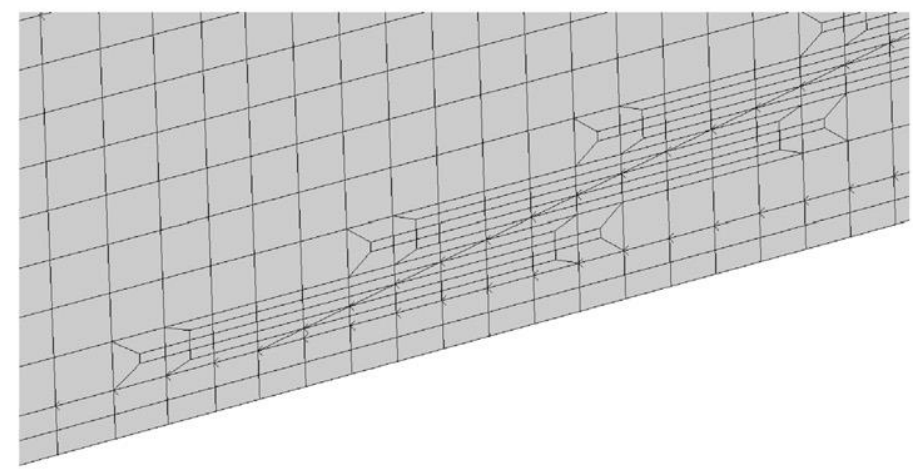

Fig. 10. Detail of the mesh at the repaired region (a) and at the IES (b) for the $\mathrm{a}^{1 / 1} 4101$ repair $\left(b^{1 / 4} 50 \mathrm{~mm}\right)$ using double reinforcement and $e^{1 / 4} 5 \mathrm{~mm}$.

a

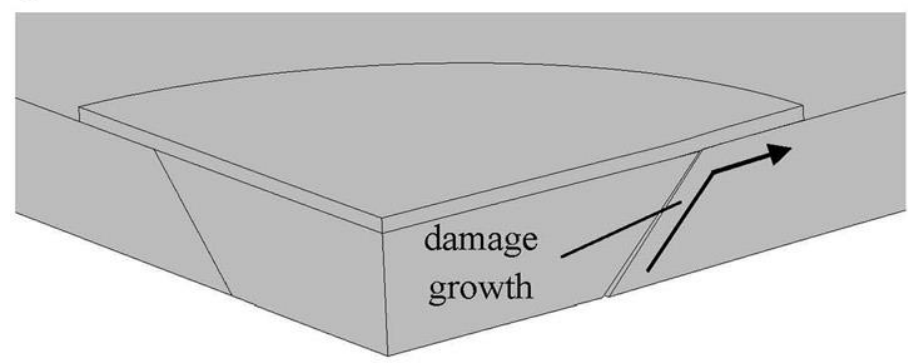

b

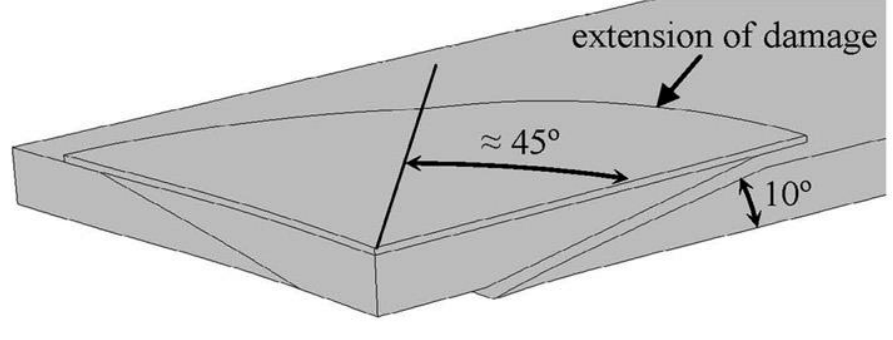

Fig. 11. Numerical failure initiation for a $\mathrm{a}^{1 / 4} 451$ repair (a) and failure for a $\mathrm{a}^{1 / 4} 101$ repair (b) (e $e^{1 / 4} 2.5 \mathrm{~mm}, b^{1 / 4} 50 \mathrm{~mm}$ and reinforcement on the outer face). 
a

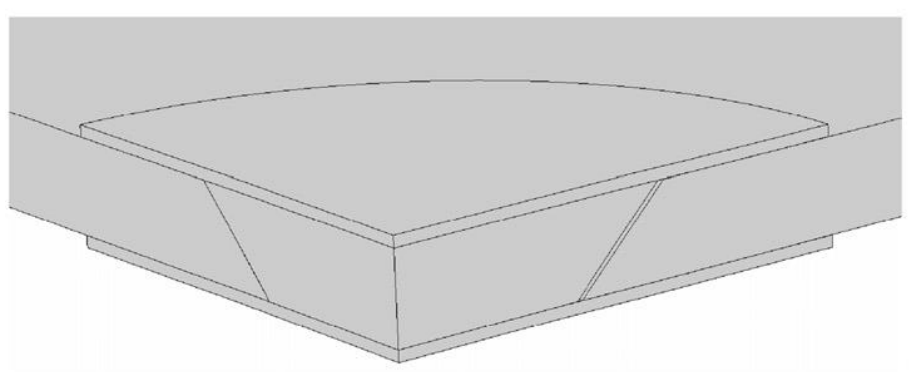

b

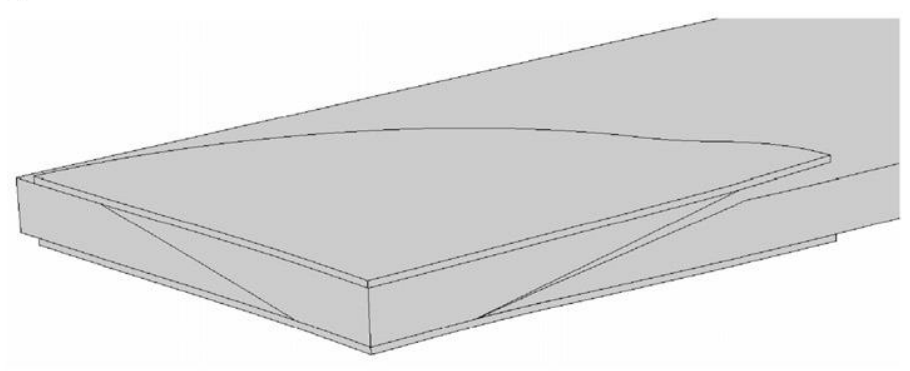

Fig. 12. Numerical failure initiation for a $a^{1 / 4} 451$ repair (a) and failure for a $\mathrm{a}^{1 / 1} 4101$ repair (b) (e $e^{1 / 4} 2.5 \mathrm{~mm}, b^{1 / 4} 50 \mathrm{~mm}$ and double reinforcement).

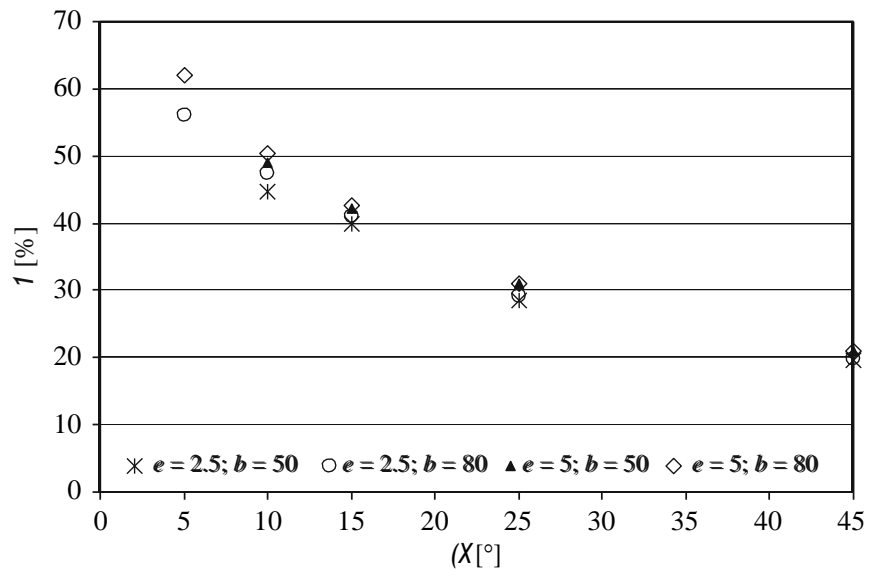

Fig. 13. $\mathrm{Z}$ as a function of a for the repairs with single reinforcement(dimensions in $\mathrm{mm})$.

plane $A$. For the smaller values of a, the overlap area between the reinforcement plies and the laminate is much larger for the inner plies than for the outer plies, which results on failure along the scarf bond and at the outer over-laminate, whilst the inner one is kept intact (Figs. 12(b)). Figs. 13 and 14 plot the values of $Z$ as a function of a for the repairs with single and double reinforcement, respectively. Fig. 13 globally shows the exponential trends formerly mentioned, with an increasing difference in the value of $Z$ between the $b^{1 / 4} 50$ and $80 \mathrm{~mm}$ repairs with the reduction of a, whose cause was already discussed. The value of $e$ showed a large impact on $Z$, with bigger values being recommended on account of higher repair efficiency. This is due to the larger shear resistant area between the laminate and over-laminating plies [38]. The highest efficiency for the $b^{1 / 4} 50 \mathrm{~mm}$ and $80 \mathrm{~mm}$ repairs (single reinforcement) was attained with the $a^{1 / 4} 101$ repair (ZE 49\%) and the $\mathrm{a}^{1 / 4} 51$ repair (ZE 62\%), respectively. These results confirm a non-negligible improvement to the standard scarf repair, which will be quantified later on this work. The results of Fig. 14 (double reinforcement) also evidence an increasing difference of $Z$ with the reduction of a between the $b^{1 / 450}$ and $80 \mathrm{~mm}$ repairs. The improvement of $Z$ was substantial, with the highest values for the $b^{1 / 4} 50$ and $80 \mathrm{~mm}$ repairs being found for the $\mathrm{a}^{1 / 4101}$ repair $(Z \mathbf{E} 58 \%)$ and the $\mathrm{a}^{1 / 451}$ repair ( $Z \mathbf{E} 72 \%$ ), respectively. The parameter $\mathbf{j}$ is introduced in Fig. 15 as the quotient between the repaired strength with single or double reinforcement and the strength of the corresponding unreinforced repairs (only for $e^{1 / 45} \mathrm{~mm}$ ), giving a clear perception of the influence of this technique on the repaired strength. A clear distinction can be made between single and double reinforcements, with the latter ones exceeding more than twice the single reinforcement corresponding values of $\mathbf{j}$. This is

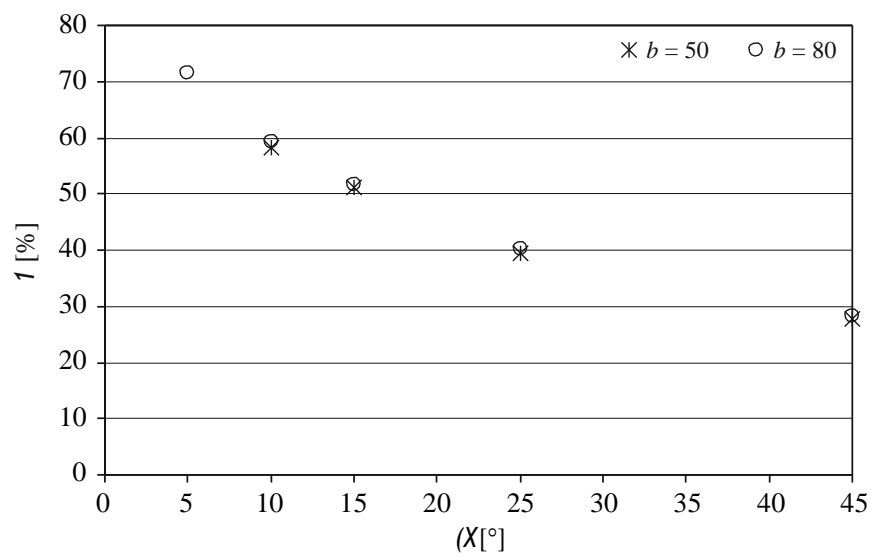

Fig. 14. $\mathrm{Z}$ as a function of a for the repairs with double reinforcement (dimensions in $\mathrm{mm})$.

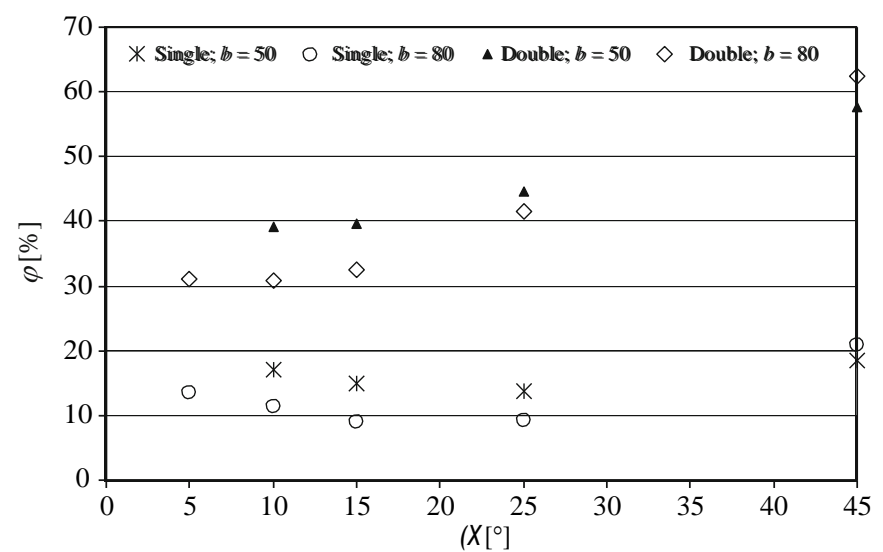

Fig. 15. jas a function of a for the repairs with single and double reinforcement (dimensions inmm).

because of the aforementioned suppression of the premature fracture near the IES and of the load eccentricity using the double reinforcement scheme. As a whole, the strength improvements with this technique are substantial, which makes it an appealing option to increase the efficiency of scarf repairs.

\section{Concluding remarks}

In this work, a comprehensive numerical analysis was performed on the tensile behaviour of three-dimensional scarf 
repairs in carbon-epoxy structures, using a ductile adhesive (Araldite $^{s}$ 2015). The finite element analysis was performed in ABAQUS $^{\mathbf{S}}$ and used Cohesive Zone Models for the simulation of damage onset and growth in the adhesive layer. Trapezoidal cohesive laws in each pure mode were used to account for the ductility of the adhesive used. Validation of the finite element methodology used was performed in previous works, which assures the legitimacy of the results. A parametric study was performed on the scarf angle, considering two values of width for the laminates to be repaired. The strength improvement increased exponentially with the reduction of the scarf angle, which implies that small angles are always recommended. The use of overlaminating plies at the outer or both of the repair faces was tested as an attempt to increase the repairs efficiency, which for scarf repairs without over-laminate was close to $50 \%$ of the undamaged laminates strength, for the smallest scarf angle. Results showed that efficiencies of approximately $70 \%$ of the undamaged strength could be attained by the use of over-laminating plies on both the laminate faces, with maximum improvements from the scarf repairs without over-laminate between approximately $30 \%$ and $60 \%$, depending on the scarf angle. Reinforcing only at the outer face of the repair, which may be the only feasible option due to accessing or disassembly difficulties, is also recommended, despite a smaller restitution of strength. Efficiencies above $70 \%$ could be achieved using smaller scarf angles than the ones tested, which would imply a larger width of the laminates to be repaired. This work allowed the establishment of principles to design scarf repairs. The quantitative predictions presented in this work should be considered valid only for the specific set of conditions selected for the analysis, whilst the generic principles established to increase the efficiency of scarf repairs are always recommended.

\section{Acknowledgements}

The authors would like to thank the Portuguese Foundation for Science and Technology for supporting the work here presented, through the individual Grant SFRH/BD/30305/2006 and the research Project PDTC/EME-PME/64839/2006.

\section{References}

[1] Wang J, Zhou Z, Vodicka R, Chiu WK. Selection of patch and adhesive materials for helicopter battle damage repair applications. Composite Structures 2009;91:278-85.

[2] Chotard TJ, Pasquiet J, Benzeggagh ML. Residual performance of scarfrepaired pultruded shapes initially impact damaged. Composite Structures 2001;53:317-31.

[3] Volkersen O. Die Niektraftverteilung in Zugbeanspruchten mit Konstanten Laschenquerschritten. Luftfahrtforschung 1938;15:41-7.

[4] Goland M, Reissner E. The stresses in cemented joints. Journal of Applied Mechanics 1944;11:17-27.

[5] Matthews FL, Kilty PF, Godwin EW. A review of the strength of joints in fibre reinforced plastics part 2: adhesively bonded joints. Composites 1982;13: 29-37.

[6] Lubkin JL. A theory of adhesive scarf joint. Journal of Applied Mechanics 1957;24:255-60.

[7] Li A, Assih J, Delmas Y. Influence of the adhesive thickness and steel plate thickness on the behaviour of the strengthened concrete beams. Journal of Adhesion Science and Technology 2000;14:1639-56.

[8] Assih J, Li A, Delmas Y. Strengthened concrete beams by gluing carbon fiber composite sheet: application of damage theory. Journal of Composites for Construction 2001;127:623-8.

[9] Kelly LG. Composite structures repair. Proceedings of the 57th meeting of the AGARD structures and materials panel. Portugal: Vimeiro; 1983. 9-14 October.

[10] Baker AA. Repair of cracked or defective metallic aircraft components with advanced fibre composites - an overview of Australian work. Composite Structures 1984;2:153-81.

[11] Baker AA, Jones R. Bonded patch repair of aircraft structures.. Dordrecht, Netherlands: Martinus Nijhoff; 1988.
[12] Smith FC, Moloney LD, Matthews FL. Fabrication of woven carbon fibre/ polycarbonate repair patches. Composites Part A: Applied Science and Manufacturing 1996;27:1089-95.

[13] Charalambides MN, Hardouin R, Kinloch AJ, Matthews FL. Adhesively-bonded repairs to fibre composite materials I: experimental. Composites Part A: Applied Science and Manufacturing 1998;29A:1371-81.

[14] Charalambides MN, Kinloch AJ, Matthews FL. Adhesively-bonded repairs to fibre composite materials I: finite element modelling. Composites Part A: Applied Science and Manufacturing 1998;29A:1383-96.

[15] Zhang H, Motipalli J, Lam YC, Baker A. Experimental and finite element analyses of the post-buckling behaviour of repaired composite panels. Composites A 1998;29A:1464-71.

[16] Rao VV, Singh R, Malhotra SK. Residual strength and fatigue life assessment of composite patch repaired specimens. Composites B 1999;30:621-7.

[17] Soutis C, Duan DM, Goutas P. Compressive behaviour of CFRP laminates repaired with adhesively bonded external patches. Composite Structures 1999;45:289-301.

[18] Adams RD, Peppiat NA. Stress analysis of adhesive bonded joint lap joints. Journal of Strain Analysis 1974;3:185-96.

[19] Frigyes T. Stress distribution in lap joints with partially thinned adherends. The Journal of Adhesion 1976;7:301-9.

[20] Allman DJ. A theory for elastic stresses in adhesive bonded lap joints Quarterly Journal of Mechanics and Applied Mathematics 1977;13:415-36.

[21] Imanaka M, Iwata T. Effect of adhesive layer thickness on fatigue strength of adhesively bonded butt, scarf and butterfly type butt joints. International Journal of Fracture 1996;80:69-76.

[22] Sato C, Ikegami K. Dynamic deformation of lap joints and scarf joints under impact loads. International Journal of Adhesion \& Adhesives 2000;20:17-25.

[23] Campilho RDSG, de Moura MFSF, Pinto AMG, Morais JJL, Domingues JJMS Modelling the tensile fracture behaviour of CFRP scarf repairs. Composites: Part B - Engineering 2009;40:149-57.

[24] Bikerman JJ. The science of adhesive joints. New York, USA: Academic Press 1968.

[25] Wang SS, Yau JF. Interfacial cracks in adhesively bonded scarf joints. AIAA Journal 1981;19:1350-6.

[26] Mortensen F, Thomsen OT. Simplified linear and non-linear analysis of stepped and scarfed adhesive-bonded lap-joints between composite laminates. Composite Structures 1997;38:281-94.

[27] Kumar SB, Sivashanker S, Bag A, Sridhar I. Failure of aerospace composite scarf-joints subjected to uniaxial compression. Materials Science and Engineering A 2005;412:117-22.

[28] Das M, Madenci E, Ambur DR. Three-dimensional nonlinear analyses of scarf repair in composite laminates and sandwich panels. Journal of the Mechanics of Materials and Structures 2008;3:1641-58.

[29] Wang CH, Gunnion AJ. On the design methodology of scarf repairs to composite laminates. Composites Science and Technology 2008;68:35-46.

[30] Tomblin JS, Salah L, Welch JM, Borgman MD Bonded repair of aircraft composite sandwich structures. Report PB2004-105463, Wichita, USA., Boeing Co., 2004.

[31] Campilho RDSG, de Moura MFSF, Domingues JJMS. Stress and failure analyses of scarf repaired CFRP laminates using a cohesive damage model. Journal of Adhesion Science and Technology 2007;21:855-970.

[32] Helms JE, Li G, Pang SS. Buckling analysis of a taper-taper adhesive-bonded composite joint. Polymer Composites 2003;24:45-52.

[33] Kumar SB, Sridhar I, Sivashanker S, Osiyemi SO, Bag A. Tensile failure of adhesively bonded CFRP composite scarf joints. Materials Science and Engineering B 2006;132:113-20.

[34] Whittingham B, Baker AA, Harman A, Bitton D. Micrographic studies on adhesively bonded scarf repairs to thick composite aircraft structure. Composites Part A: Applied Science and Manufacturing 2009;90:1419-32.

[35] Robson JE, Matthews FL, Kinloch AJ. The strength of composite repair patches: a laminate analysis approach. Journal of Reinforced Plastics and Composites 1992;11:729-42.

[36] Armstrong KB, Barrett R. Care and repair of advanced composites. Warrendale, USA: Society of Automotive Engineers; 1998.

[37] Sherwin GR. Non-autoclave processing of advanced composite repairs. International Journal of Adhesion \& Adhesives 1999;19:155-9.

[38] Tzetzis D, Hogg PJ. Experimental and finite element analysis on the performance of vacuum-assisted resin infused single scarf repairs. Materials and Design 2008;29:436-49.

[39] Bauer J, Maier AE. On aircraft repair verification of a fighter A/C integrally stiffened fuselage skin. In: Proceedings of the 79th meeting of the AGARD structures and materials panel, Seville, Spain, 3-5 October 1994.

[40] Hart-Smith LJ Adhesive-bonded scarf and stepped-lap joints. NASA technical report CR-112237, Hampton, USA, Langley Research Centre, 1973.

[41] Kim HS, Lee SJ, Lee DG. Development of a strength model for the co-cured stepped lap joints under tensile loading. Composite Structures 1995;32: 593-600.

[42] Ahn SH, Springer GS. Repair of composite laminates-I: test results. Journal of Composite Materials 1998;32:1036-74.

[43] Du J, Salmon FT, Pocius AV. Modeling of cohesive failure processes in structural adhesive bonded joints. Journal of Adhesion Science and Technology 2004;18:287-99.

[44] Adkins DW, Pipes RB Tensile behaviour of bonded scarf joints between composite adherends. In: Proceedings of the fourth Japan-US conference on composite materials. Washington, DC, USA, 27-29 June 1988. 
[45] Odi RA, Friend CM. A comparative study of finite element models for the bonded repair of composite structures. Journal of Reinforced Plastics and Composites 2002;21:311-32.

[46] Mollenhauer DH, Fredrickson BM, Schoeppner GA, Iarve EV, Palazotto AN Moire interferometry measurements of composite laminate repair behavior: influence of grating thickness on interlaminar response. Composites Part A Applied Science and Manufacturing 2008;39:322-1330.

[47] Campilho RDSG, de Moura MFSF, Domingues JJMS. Using a cohesive damage model to predict the tensile behaviour of CFRP single-strap repairs. International Journal of Solids and Structures 2008;45:1497-512.

[48] Campilho RDSG, de Moura MFSF, Ramantani DA, Morais JJL, Domingues JJMS Buckling behaviour of carbon-epoxy adhesively-bonded scarf repairs. Journal of Adhesion Science and Technology 2009;23:1493-513.

[49] Pipes RB, Pagano NJ. Interlaminar stresses in composite laminates under uniform axial extension. Journal of Composite Materials 1970;4:538-48.

[50] Stenger F, Chaudhuri R, Chiu J. Sinc solution of boundary integral form for twodimensional bi-material elasticity problems. Composites Science \& Technology 2000;60:2197-211.

[51] Chaudhuri RA, Chiu SHJ. Three-dimensional asymptotic stress field in the vicinity of an adhesively bonded scarf joint interface. Composite Structures 2009;89:475-83.

[52] Gacoin A, Lestriez P, Assih J, Objois A, Delmas Y. Comparison between experimental and numerical study of the adhesively bonded scarf joint and double scarf joint: influence of internal singularity created by geometry of the double scarf joint on the damage evolution. International Journal of Adhesion \& Adhesives 2009;29:572-9.

[53] Hart Smith LJ. Adhesive-bonded scarf and stepped-lap joints. Long Beach, USA: Mcdonnell-Douglas Corp.; 1973.

[54] Oplinger DW. Mechanical fastening and adhesive bonding. In: Peters ST, editor. Handbook of composites. London, UK: Chapman \& Hall; 1998.

[55] Baker AA. Joining and repair of aircraft composite structures. Mechanical Engineering Transactions 1996;1-2:1-59.

[56] Wang CH, Gunnion AJ. Optimum shapes of scarf repairs. Composites Part A: Applied Science and Manufacturing 2009;40:1407-18.

[57] Soutis C, Hu FZ. Failure analysis of scarf-patch-repaired composite laminates loaded in compression. AIAA Journal 2000;38:734-40.

[58] Soutis C, Hu FZ. Strength analysis of adhesively bonded repairs. In: Soutic LT, editor. Recent advances in structural joints and repairs for composite materials. London, UK: Kluwer Academic Publishers; 2003.

[59] Hu FZ, Soutis C. Strength prediction of patch repaired CFRP laminates loaded in compression. Journal of Composites Science \& Technology 2000;60: $1103-14$.

[60] Qian ZQ, Akisanya AR. An experimental investigation of failure initiation in bonded joints. Acta Materialia 1998;46:4895-904.

[61] Qian ZQ, Akisanya AR. An investigation of the stress singularity near the free edge of scarf joints. European Journal of Mechanics - A/Solids 1999;18: 443-63.
[62] Campilho RDSG, de Moura MFSF, Ramantani DA, Morais JJL, Domingues JJMS. Tensile behaviour of three-dimensional carbon-epoxy adhesively-bonded single and double-strap repairs. International Journal of Adhesion \& Adhesives 2009;29:678-86.

[63] RDSG Campilho, de Moura MFSF, JJMS Domingues, Morais JJL. Computational modelling of the residual strength of repaired composite laminates using a cohesive damage model. Journal of Adhesion Science and Technology 2008;22:1565-91.

[64] Marques EAS, da Silva LFM. Joint strength optimization of adhesively bonded patches. The Journal of Adhesion 2008;84:917-36.

[65] de Moura MFSF Campilho, RDSG Gonc-alves JPM. Crack equivalent concept applied to the fracture characterization of bonded joints under pure mode I loading. Composites Science and Technology 2008;68:2224-30.

[66] de Moura MFSF, Campilho RDSG, Gonc-alves JPM. Pure mode II fracture characterization of composite bonded joints. International Journal of Solids and Structures 2009;46:1589-95.

[67] Gacoin A, Assih J, Objois A, Delmas Y. Experimental studies on adhesivelybonded scarf joints: influence of natural ageing on progressive damage. Journal of Adhesion Science and Technology 2007;21:871-82.

[68] Gunnion AJ, Herszberg I. Parametric study of scarf joints in composite structures. Composite Structures 2006;75:364-76.

[69] Odi RA, Friend CM. An improved 2D model for bonded composite joints. International Journal of Adhesion \& Adhesives 2004;24:389-405.

[70] Campilho RDSG, de Moura MFSF, Domingues JJMS. Modelling single and double-lap repairs on composite materials. Composites Science and Technology 2005;65:1948-58.

[71] Johnson CL. Effect of ply stacking sequence on stress in a scarf joint. AIAA Journal 1989;27:79-86.

[72] Harman $A B$, Wang $\mathrm{CH}$. Improved design methods for scarf repairs to highly strained composite aircraft structure. Composite Structures 2006;75:132-44.

[73] Soutis C, Hu FZ Repair design of composites and efficiency of scarf patch repairs. In: Proceedings of the 11 th international conference on composite materials. Melbourne, Australia, 14-18 July 1997.

[74] Brink DD, Mailand JC, Levi CG, Leckie FA. Deformation behaviour of model MMC scarf joints. Materials Science and Engineering: A 2000;281: 113-25.

[75] Savage G, Oxley M Repair of composite structures on Formula 1 race cars. Engineering Failure Analysis doi:10.1016/j.engfailanal.2008.11.006.

[76] Zimmerman K, Liu D. Geometrical parameters in composite repair. Journal of Composite Materials 1995;29:1473-87.

[77] Hamoush S, Shivakumar K, Darwish F, Sharpe M, Swindell P. Defective repairs of laminated solid composites. Journal of Composite Materials 2005;39: 2185-96.

[78] Baker AA, Chester RJ, Hugo GR, Radtke TC. Scarf repairs to highly strained graphite/epoxy structure. International Journal of Adhesion \& Adhesives 1999;19:161-71. 